\title{
Management of postpneumonectomy empyema and bronchopleural fistula
}

\author{
Ivan Azevedo ${ }^{1}$, Ricardo L. Oliveira ${ }^{2}$, Paula A. Ugalde ${ }^{3}$ \\ ${ }^{1}$ Division of Thoracic Surgery, Department of Oncology Oncobeda, Doctor Beda General Hospital, Rio de Janeiro, Brazil; ${ }^{2}$ Division of Thoracic \\ Surgery, Santa Casa de Misericórdia da Bahia, Salvador, Brazil; ${ }^{3}$ Department of Pulmonology and Thoracic Surgery, Institut Universitaire de \\ Pneumologie et Cardiologie de Quebec, Québec, QC, Canada \\ Contributions: (I) Conception and design: All authors; (II) Administrative support: All authors; (III) Provision of study materials or patients: All \\ authors; (IV) Collection and assembly of data: All authors; (V) Data analysis and interpretation: All authors; (VI) Manuscript writing: All authors; (VII) \\ Final approval of manuscript: All authors. \\ Correspondence to: Paula A. Ugalde Figueroa, MD. Division of Thoracic Surgery, Institut Universitaire de Cardiologie et de Pneumologie de Quebec, \\ 2725 Chemin Ste-Foy, Quebec City, Quebec, Canada. G1V4G5. Email: paula.ugalde@criucpq.ulaval.ca.
}

\begin{abstract}
Although the number of pneumonectomies performed worldwide is decreasing due to epidemiological changes in lung cancer, increased awareness of postoperative complications of pneumonectomy plays a major role in the proper clinical management and ultimately in the quality of life and survival rate of patients. Postpneumonectomy empyema is a rare but serious complication of pneumonectomy. The prognosis of postpneumonectomy empyema patients mainly depends on when the complication appears and the presence or absence of a bronchopleural fistula (BPF). The majority of empyema will occur within the first 3 months after surgery. The management of postpneumonectomy empyema is a challenge to thoracic surgeons due to the number of surgical approaches available and a lack of consensus as to the best approach. It can vary from a simple rib resection and open drainage to a complete thoracoplasty. Unfortunately, after pneumonectomy, patients who develop BPF and empyema will present prolonged hospitalization and are at risk of high morbidity and mortality rates. Consequently, successful therapy might be difficult to achieve, that is why is so important to well select your strategy. Though this remains an area of controversy in the field of thoracic surgery, accurate and expedited diagnosis is critical to achieve a cure. Regardless of the technique adopted for treatment, adequate pleural drainage, definitive closure of the BPF, sterilization of the pleural cavity, and obliteration of residual space are the key factors to favorable outcomes. In this article, the authors aim to discuss in detail the management strategy based on the clinical evolution of patients with postpneumonectomy empyema and BPF.
\end{abstract}

Keywords: Pneumonectomy; empyema; bronchopleural fistula

Received: 03 February 2020; Accepted: 06 March 2020; Published: 10 April 2021.

doi: $10.21037 /$ shc.2020.03.11

View this article at: http://dx.doi.org/10.21037/shc.2020.03.11

\section{Introduction}

Pneumonectomy is the surgical removal of an entire lung and is frequently performed for the management of bronchogenic carcinoma. Pneumonectomy is required when a tumor is located in a central position, such as the main stem bronchus, or when a tumor extends across a major fissure. Rarely, pneumonectomy is performed for the treatment of metastasis; inflammatory lung diseases, such as pulmonary tuberculosis, fungal infections, bronchiectasis; or other benign diseases, such as traumatic lung injury and congenital diseases (1). Despite refinements in both surgical technique and postoperative care of patients who undergo lung cancer resection, pneumonectomy still has very high morbidity and mortality when compared with other types of lung resection (2). Although the number of pneumonectomies performed worldwide is 
decreasing due to epidemiological changes in lung cancer, increased awareness of postoperative complications of pneumonectomy plays a major role in appropriate clinical management to achieve good outcomes and ultimately high survival rates.

Empyema after pneumonectomy is an uncommon but serious complication, with a reported incidence of $5 \%$ to $10 \%$ and mortality of up to $20 \%(3,4)$. Most postpneumonectomy empyemas $(75 \%)$ occur within the first 3 months after surgery (5). Empyema years after the procedure is rare. The prognosis of patients with postpneumonectomy empyema mainly depends on when the complication appears and the presence or absence of a bronchopleural fistula (BPF) (6). Over the years, various strategies have been proposed for the management of postpneumonectomy empyema and $\mathrm{BPF}$, ranging from simple rib resection and open drainage to a complete thoracoplasty. This focused issue of the Shanghai Chest Fournal, details "The Role of Pneumonectomy in Thoracic Surgery in The Third Millennium" and in this article, we will discuss the management of postpneumonectomy empyema and BPF.

\section{Clinical features}

Empyema thoracis is defined as the collection of pus in the pleural space. It has been recognized since the time of Hippocrates and historically has been associated with high mortality (7). The name comes from Greek word empyein meaning pus producing; pus and fluid from infected tissue collects in the body cavity.

The removal of an entire lung is associated with a variety of predictable anatomic changes and a number of potential complications that involve the respiratory system and the pleural space. The absence of the lung in the pleural cavity predisposes to fluid accumulation in this space. This fluid can be colonized by bacteria and cause empyema. This can be aggravated by the presence of bronchopleural fistula, which is the result of bronchial stump dehiscence, thus directly connecting the airways with the pleural cavity. The presence of the fistula offers a greater challenge in treatment and a worse prognosis for these patients. Diabetes mellitus and chronic obstructive pulmonary disease are independent risk factors for postoperative BPF $(7,8)$. Age over 70 years, anemia, poor nutrition, hypoalbuminemia, systemic use of steroids, empyema, neoadjuvant therapy with chemotherapy or radiation, and tracheostomy have also been described as risk factors (9-17). Postoperative mechanical ventilator assistance with positive pressure can affect stump healing and the incidence of dehiscence $(11,12,14)$.

Early postpneumonectomy empyema usually occurs up to 14 days postoperatively and is commonly associated with a bronchial fistula. Late empyema, in which the infection is most often acquired hematogenously, occurs, by definition, more than three months after pneumonectomy. There are reports of empyema diagnosed up to 40 years after the pneumonectomy procedure.

Patients with early infection of the pleural space generally present with one or more of the following symptoms: fever, malaise, thoracic pain, or dyspnea. Occasionally, expectoration of purulent sputum is noted if a $\mathrm{BPF}$ is present. In contrast, patients with late empyema show a pattern of chronic infection with nonspecific symptoms such as flu-like symptoms, mild malaise, weight loss, low grade fever, and anorexia. In rare cases, the infection can spread through the chest wall and drain through the overlying skin; this is condition is designated empyema necessitans. Almost $50 \%$ of cases of both early and late empyema are polymicrobial, and the microorganisms most often found in these infections are Staphylococcus aureus and Pseudomonas aeruginosa (18).

\section{Management strategy}

\section{Diagnosis}

Diagnostic investigation begins with a thorough clinical evaluation and imaging tests. Chest $\mathrm{x}$-rays are useful to evaluate contralateral mediastinal deviation, the appearance of air in the pleural collection or a sudden change in an air-fluid level that was previously stable, which suggests a bronchial stump fistula. A contrast chest computed tomography (CT) scan should always be acquired to define the anatomy of the pleural space, the position of diaphragm and the condition of the contralateral lung. A chest CT can also identify peripheral rind enhancement and air-fluid levels and be used to measure the density of the fluid. The chest CT findings may suggest localized or multi-loculated empyema.

Flexible bronchoscopy can confirm or rule-out most BPFs and can be used to establish the precise location and the size of the fistula for therapeutic planning (Figure 1). In patients with microfistulas, the visual component of the exam may be insufficient for diagnosis, and a radiopaque contrast can be used to enhance visualization of the path of the fistula. Lastly, empyema is confirmed by puncture of the postpneumonectomy space for pleural fluid analysis. The 

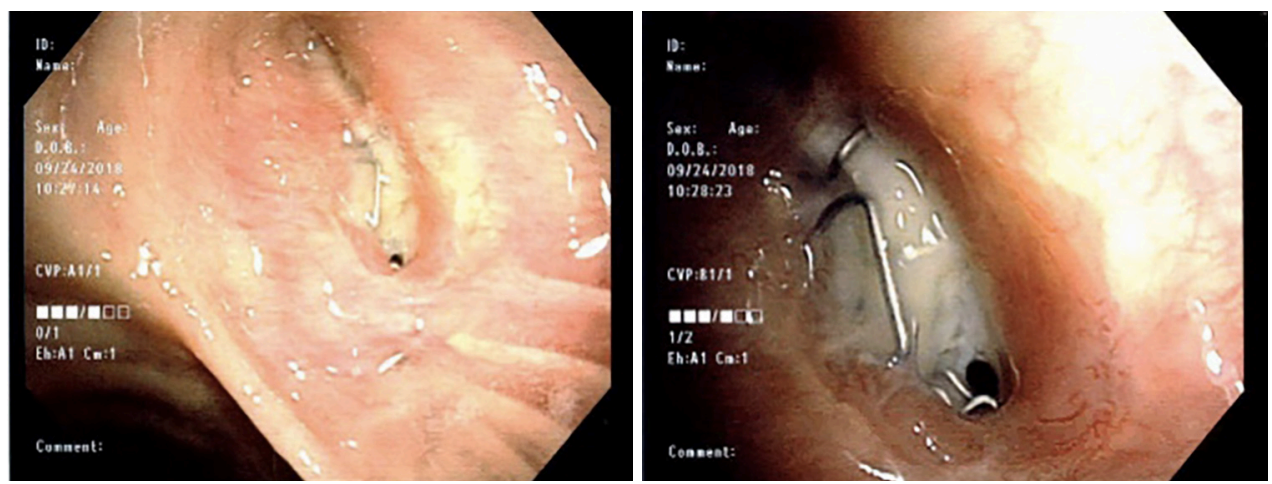

Figure 1 Endoscopic views of a bronchopleural fistula.

diagnosis is confirmed by the presence of pus, $\mathrm{pH}<7.25$, and positive microbiological results (19).

\section{Surgical management}

The management of postpneumonectomy empyema remains a challenge to thoracic surgeons due to the number of surgical approaches available and a lack of consensus as to the best approach. Operative management of postpneumonectomy empyema is determined in general by two factors: the timing of the empyema in relation to the surgery and the presence or absence of a BPF. In the acute postoperative stage, the empyema is initially managed with a closed chest tube until the patient is clinically stable and can undergo a surgical procedure. Historically, treatment has ranged from a simple rib resection and open drainage to a complete thoracoplasty depending on the complexity of the case and the extent of the complication. The degree of invasiveness of the technique chosen to approach empyema depends on the chronicity of the empyema, the presence of bronchial fistula as well as the experience of the assistant surgical team. Currently, with the advancement of technology and surgical techniques, minimally invasive approaches using video-assisted thoracic surgery have been shown to be effective in selected cases. The most clinically relevant study of the management of postpneumonectomy empyema was likely a report by Clagett and Geraci (20) in 1963 describing rib resection with open thoracotomy, cavity sterilization after successive debridement, and posterior closure filling the cavity with antibiotic solution after 6 to 8 weeks. Due to technological advances and new diagnostic and treatment tools, we tend to take a less aggressive approach in selected patients in the current era.

The primary cause of empyema has also changed over time. In the past, tuberculous empyema was highly prevalent, and its exclusive treatment was an aggressive approach to the pleural space. With the advent of tuberculostatic medications, this approach to the pleura was reduced to use in patients with complex complications, such as phase 3 empyema. However, bacterial strains are increasingly resistant to antibiotics, which is currently a major cause of pleural complications necessitating a surgical approach to the pleural space.

\section{Open thoracotomy}

Open window toracostomy is a definitive and potentially lifesaving procedure for patients with little physiologic reserve and a severely infected pleural space. It consists in a open thoracostomy that has two main goals: allow passive drainage of the infected pleural space by gravity and create a one-way valve that will allow egress of fluid from the chest cavity without the return of air. It was first described by Leo Eloesser (21) in 1935 as a surgical treatment option for patients with tuberculosis and pleural space infections associated with BPFs (22). The technique was later modified by Symbas (23) and coworkers and consists of creating a window in the lower part of the pleural cavity (usually between the 6th and 8th ribs).

Initially, with careful review of the preoperative chest imaging, the steepest zone near the diaphragm is determined to properly place a chest tube sufficient to evacuate the pleural space (Figure $2 A$ ). More importantly, this tube may later be used as a physical landmark in the operating room to indicate the optimal location for the open thoracostomy. An inverted U-shaped incision is made at the skin and extended through the soft tissues to the level of the chest wall using electrocautery. After splitting 

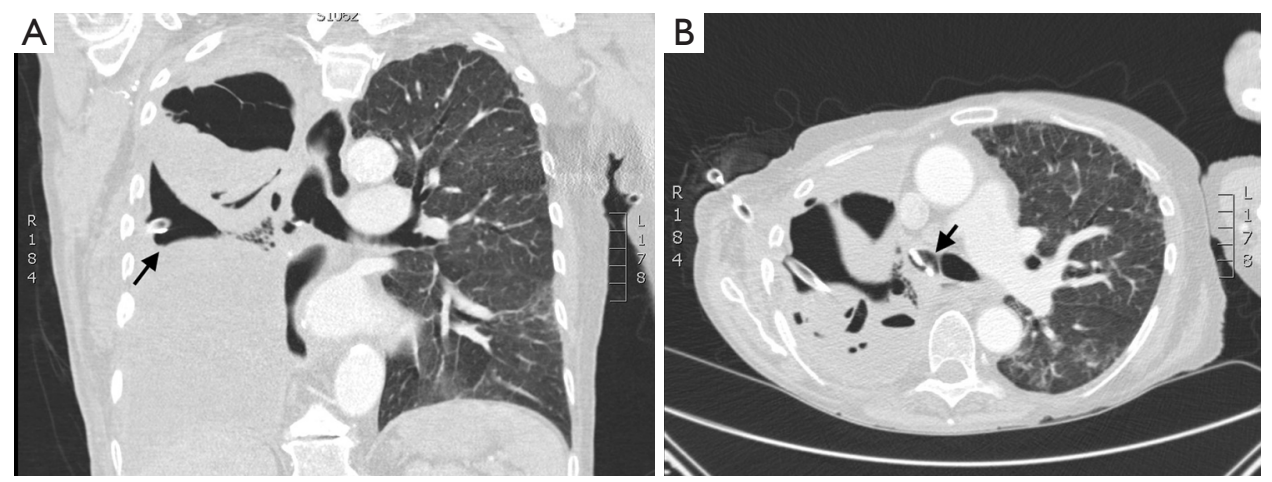

Figure 2 Endoscopic views of a bronchopleural fistula.

the muscles of the thoracic wall and the ribs are exposed, segments of two or three adjacent ribs are transected. The U-shaped skin flap is fixed against the diaphragm, creating a epithelialized tract from the postpneumonectomy space to the outside $(21,23)$. A crucial aspect to the creation of an Eloesser flap is selection of an optimal position to allow effective, passive drainage and relatively easy access for open wound packing and patient comfort (Figure 2).

Clagett modified the procedure further by creating a window thoracostomy with open surgery, irrigating with antibiotics, and then closing the window (20). The greatest differences between the Eloesser flap and a Clagett window are that the Clagett window is considerably larger than an Eloesser flap and that the Clagett window was designed to be a temporary strategy to allow decontamination of the pleural space with a subsequent closure (24) after filling the pleural space with antibiotic solution. In contrast, the Eloesser flap is intended to create a permanent drainage window into the pleural space (25). Stafford and Clagett reported a success rate of $75-88 \%$ in their series $(25)$. Failure, however, was most often due to recurrent BPF and recontamination of the pleural space (26). To decrease the recurrence rate, Pairolero and associates modified the Clagett procedure by adding one more step to the operation, the transposition of extrathoracic skeletal muscle to reinforce the bronchial stump step before filling the pleural cavity with antibiotic solution. With this new approach, $84 \%$ of their patients had a healed chest wall with no evidence of infection, and $86 \%$ of BPFs remained successfully closed (18).

\section{Muscle flap transposition}

Intrathoracic muscle transposition was described by
Abrashoff in 1911 for closure of BPF (27). Since then, muscle flaps have been utilized to obliterate spaces, close $\mathrm{BPF}$, and reinforce tracheobronchial and esophageal anastomoses. Muscle flaps are considered a good option to fill a contaminated space with or without a BPF because of their excellent blood supply and their ability to reach almost any location in the pleural cavity. The two predominant surgical principles to keep in mind are (I) leave no residual pleural space and (II) ensure that a sufficient number of flaps are available so that any intrathoracic space can be filled. To achieve successful pleural cavity obliteration with muscle flaps, some basic steps should be followed. The patient must be clinically stable with no signs of sepsis, with appropriate antibiotic coverage (based on the sensitivity of the microbiological cultures). They must undergo wide cavity debridement, and in the presence of a BPF, closure should be accomplished. When a BPF is identified, its edges are debrided, and the fistula is closed with an omental flap brought up through an anterior diaphragmatic incision and tacked around the fistula with 3-0 sutures (omentopexy) (27).

Anatomical knowledge of the vascular pedicles of the chest wall musculature is essential to mobilize the flaps used to fill the pleural space. Each muscle has its own particularities and can reach and fill spaces of different sizes. The latissimus dorsi (LD) muscle flap is the largest and is easiest to harvest through a standard incision or a separate small rib resection. Its predominant blood supply is from the thoracodorsal artery. The pedicled LD can be easily applied to apical and mid-intrathoracic spaces. The pectoralis major $(\mathrm{PM})$ is the second largest chest wall muscle. It has a dual blood supply from the predominant thoracoacromial artery to the major pedicle and from the internal mammary artery to the major pedicle and the secondary pedicles. The PM may be used as a reverse turnover flap or be placed directly 
into the wound. It requires a $5-\mathrm{cm}$ rib resection for entry into the chest. A PM flap is the flap of choice for sternal infections but ranks after the LD and serratus anterior for the pleural space and is best suited for apical spaces. The serratus anterior is often a second choice to create a flap for filling a pneumonectomy space, and it is particularly good for filling a small space. The blood supply comes from the lateral thoracic artery, and it can rotate into the chest through the primary incision. Flaps from the rectus abdominis are usually used to repair defects in the lower third of the sternum. Its blood supply comes from the superior epigastric artery (28). Rectus abdominis flaps can also be applied as a filling of the pleural cavity especially in the basal zones but are usually the last choice for this purpose.

In general, an LD flap is used first. If there is failure to achieve full control of the pleural infection, other muscles are used to fill the entire space, depending on anatomical location and size of the space. The pneumonectomy space in a typical adult can usually be filled about 30 to $40 \%$ by LD flaps, followed by 20 to $30 \%$ by PM flaps and 10 to $15 \%$ by omental or rectus abdominis flaps $(26,29)$. Following transposition of the muscle flaps, the wound is closed primarily, and chest tubes are connected to a negative pressure unit for 7 to 10 days while appropriate antibiotics are given.

\section{Thoracoplasty}

Originally conceived to collapse the cavities of lungs affected by tuberculosis, thoracoplasty reduces the thoracic cavity by removing the ribs. The technique was later extended to the treatment of empyematic cavities. In 1937, Alexander described extrapleural subperiosteal thoracoplasty, the same technique used to this day. Because of the advent of less aggressive procedures, like muscle transposition to fill the pleural space, thoracoplasty was almost completely abandoned (30). However, despite having the bad reputation of being a mutilating operation, studies in the last 25 years have shown that thoracoplasty can be an excellent therapeutic option in selected patients, used alone or in combination with flap transposition to fill the residual space $(31,32)$. Thoracoplasty may be indicated if the postpneumonectomy space is too large to be filled with muscle flaps. Properly performed, thoracoplasty remains a safe and effective solution for difficult intrathoracic space problems, especially in combination with other filling procedures, provided that the underlying infection is controlled.
Adequate drainage of the space for the control of infection is mandatory for successful thoracoplasty.

The technique for thoracoplasty consists of good exposure of the rib cage with a wide posterolateral incision with scapula elevation to allow the handling of the upper ribs. The rib resection should be done via the subperiosteal and extrapleural plane. Some authors advocate for the removal of the first rib to promote a good collapse of the thoracic apical region, but in some patients, extrapleural detachment (apicolisis described by Semb) (33) from the pleural dome has led to good results with vertical occupation of these cavities. An important step is rib disarticulation at the costovertebral joint, which prevents poor occupation of the posterior gutter. Some authors cite the removal of transverse processes, but this technique is most commonly utilized in patients with severe and symptomatic scoliosis (34).

\section{Accelerated treatment}

A study from Poland and Switzerland conducted from July 1995 to October 2005 supported the concept of "accelerated" management of early postpneumonectomy empyema without an open window thoracotomy (19). Patients were placed under general anesthesia, and a double-lumen endotracheal tube was placed for ventilation. The technique consisted of radical debridement of the pleural cavity through a thoracotomy and packing the cavity with wet dressings of povidone-iodine. A chest tube under negative pressure was left in place. This procedure was repeated in the operating room every 48 hours, until the chest cavity was "macroscopically clean". If a BPF was present, the bronchial stump insufficiency was closed and secured by omentopexy. Finally, the pleural space was obliterated with antibiotic solution containing $0.3 \mathrm{~g}$ of netilmicin, $2.2 \mathrm{~g}$ of ampicillin/clavulanic acid, and $1 \mathrm{~g}$ of vancomycin per liter of saline. The median number of interventions until final closure of the chest was 3 (range, $1-8$ ), and the median hospitalization time was 18 days (range, 9-134 days). The patients appreciated having their chests closed generally within a week and being free of a drain or chest wall window. This technique is not considered a good option for patients with chronic empyema with BPF.

\section{Closed irrigation}

Pleural space irrigation has been advocated as an alternative 

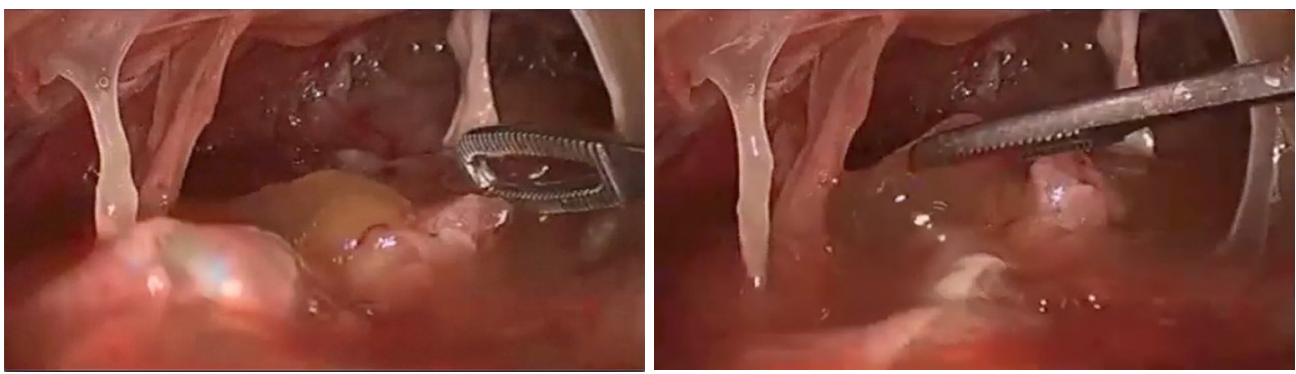

Figure 3 Video-assisted thoracoscopic surgery (VATS) for the management of empyema after pneumonectomy.

method of treating empyema and space after pneumonectomy, especially with early infections. Irrigation may also be useful in sterilizing a chronic empyema in patients who would not readily tolerate an extensive and aggressive procedure $(35,36)$. To reduce morbidity and length of hospital stay of patients with early postpneumonectomy empyema, Gharagozloo and colleagues explored the technique of pleural space irrigation as a further modification of the "Clagett" procedure (37). All patients were treated with debridement thoracotomy and one-time surgical treatment of BPF. Then, the pleural space was irrigated with $0.1 \%$ povidone-iodine solution (Betadine; $40 \mathrm{~mL} / \mathrm{h}$ ) through 2 catheters placed in the 2nd intercostal space and evacuated with 2 chest tubes for 7 days. On day 8 , the povidone- iodine irrigation was discontinued, and the pleural space was irrigated with normal saline solution ( $40 \mathrm{~mL} / \mathrm{h}$ ) for 24 hours. On day 9 , the chest tube drainage fluid was stained to assess the status of the infection. If cultures were negative, the pleural space was filled with $2 \mathrm{~L}$ of DAB solution (gentamicin $80 \mathrm{mg} / \mathrm{L}$, neomycin $500 \mathrm{mg} / \mathrm{L}$, and polymyxin B $100 \mathrm{mg} / \mathrm{L}$ ), and the irrigation and drainage catheters were removed. This technique requires a single surgical procedure and results in significantly shorter hospitalization and decreased morbidity in a selected subset of patients with postpneumonectomy empyema.

The combination of optimal management of the postpneumonectomy bronchial stump, either to treat or avoid BPF, and complete debridement of the pleural cavity and pleural irrigation may be comparable with open drainage with packing of the contaminated space. The main goals are to keep the infection under control and to sterilize the cavity. Inasmuch as there was no recurrence of BPF or empyema in Gharagozloo's series (37), pleural space irrigation followed by obliteration of the pleural space with an antibiotic solution represents a good option for patients with early post-pneumonectomy empyema and no BPF or a small BPF.

\section{Video-assisted thoracoscopic surgery (VATS)}

Nowadays, a minimally invasive approach is being increasingly adopted in the therapeutic arsenal to treat postpneumonectomy empyema (Figure 3). Local control of the infection through debris removal and cavity lavage is performed minimally invasively by avoiding an open thoracotomy or even thoracoplasty. In 3 publications reporting the use of video-assisted thoracoscopic surgery (VATS) for the management of empyema after pneumonectomy, the thoracoscopic procedure was combined with the pleural irrigation technique. In all 3 series, there were no treatment failures during a 21-month follow-up (38-40). More recently, a publication by Gossot and colleagues reported a series of 11 cases of empyema in postpneumonectomy patients (41). In this series, pleural irrigation was not used as part of their strategy, the patients had immediate chest tube drainage and underwent emergency thoracoscopic debridement of the empyema. In 3 cases, reoperation was necessary due to the maintenance of infectious signs and the patients underwent open drainage thoracostomy. The successful rate of this series was $73 \%$.

All 4 series proved that the VATS approach is useful for selected patients with early postpneumonectomy empyema including those with small BPFs, although with a very limited number of patients. However, the method seems difficult to apply in patients with late postpneumonectomy empyema and is contraindicated for patients with large BPFs. The main advantages of thoracoscopic approach are the high cure rate and the dramatically reduction in chest drainage duration and hospital stay. VATS treatment does not preclude more aggressive surgical management in cases of failure or relapse. 


\section{Bronchopleural fistula management}

\section{Endoscopic approach}

Endoscopic treatment of BPF can be performed either by flexible or rigid bronchoscopy and with either sedation or general anesthesia. The approach is physician dependent. Different materials have been used to close fistulas; however, the principle is the same: to achieve immediate mechanical closure by directly application of the substance followed by scar tissue formation.

In the short-term, primary endoscopic closure of BPFs has the potential benefits of decreasing air leak and pleural contamination and preventing contralateral aspiration of the pleural fluid. In long-term, it is also possible to achieve definitive BPF closure with an endoscopic approach. Success rate is related to the fistula size (42-44). In a retrospective series of 35 patients who underwent bronchoscopy repair of BPFs after pneumonectomy, Cardillo and colleagues demonstrated a successful repair in $92.3 \%$ of patients with BPFs $\leq 2 \mathrm{~mm}$ in size, $71.4 \%$ for $\mathrm{BPF}>2$ and $<3 \mathrm{~mm}$, $80 \%$ for $\mathrm{BPF}>3$ and $<6 \mathrm{~mm}$, and only $33.3 \%$ in patients with $\mathrm{BPF}>6 \mathrm{~mm}$ (43). In patients with BPF with mucosal necrosis, the failure rates are high, and therefore, surgical treatment is advisable in these patients (43).

\section{Biological glues}

Different types of biological glues have been used to close BPFs including fibrin-based glues, cyanoacrylate-based glues (e.g., Histoacryl ${ }^{\circledR}$ ), and albumin-glutaraldehyde tissue adhesive $\left(\right.$ BioGlue $\left.^{\circledR}\right)(45,46)$. The glue is directly applied in the fistula through a thin-catheter introduced in the working channel of a flexible bronchoscope. A plug promotes mechanical closure of the fistula, and an instantaneous cessation of air leak is expected (43). The glue may also be injected in the submucosa with a $21 \mathrm{G}$ needle in order to decrease plug displacement (45). It is not unusual to need to repeat the procedure (47). Regardless of the substance and technique used, posterior inflammatory tissue growth helps achieving long-term BPF closure (48). This technique seems to work best for very small fistulae (up to $3 \mathrm{~mm}$ ) (45).

\section{Sclerosing agents}

Sclerosing agents are also used to manage BPFs and may be applied directly to the mucosa of the fistula or injected in the submucosa. Initially, a local edema might occlude the trajectory; however, the subsequent inflammatory reaction and scar tissue formation are the main mechanisms for definitive BPF closure (49,50). Repeated applications are frequently needed. Stratakos and colleagues reported an $81.8 \%$ success rate in a series of 11 patients with postpneumonectomy or postlobectomy $\mathrm{BPF} \leq 5 \mathrm{~mm}$ treated with mucosal application of melted silver nitrate applied through a flexible bronchoscope and using a cytology brush (51). Varoli and coworkers successfully treated 23 out of 35 patients $(65 \%)$ with partial postpneumonectomy or postlobectomy bronchial stump dehiscence (up to $10 \mathrm{~mm}$ ) by sequential injections of $4-5 \mathrm{~mL}$ of $2 \%$ polidocanol in the fistula submucosa, achieving complete healing after a mean of 5.5 weeks (52).

\section{Occluding devices}

Some occluder devices originally used for transcatheter closure of cardiac septal defects or patent ductus arteriosum closure, such as Amplatzer septal occluder (ASO), Amplatzer ductal occluder (ADO) and Amplatzer vascular plug (AVP) (AGA Medical, Golden Val- ley, Minn., USA), have been reported as options for BPF closure (53-56). ASO and ADO are double-disk occluders with a waist between them better suited for large fistulae with long communicating tract $(>10 \mathrm{~mm})$ before the pleural cavity (55). AVP is a selfexpandable cylindrical device used for vessel occlusion mostly applied for small short-necked and pin-shaped BPFs (56). All three devices are deployed under direct bronchoscopic and fluoroscopic vision (55). Experience with these techniques for BPF treatment is limited but with promising results. Fruchter and colleagues published a series of 31 patients with postpneumonectomy and postlobectomy $\mathrm{BPF}$ treated with occluding devices. Immediate BPF closure was observed in 30 out of 31 patients (96\%). After 6 months, 22 patients were alive, and all the devices were covered by granulation tissue (57).

Recently, Han and colleagues reported their experience with an endoscopic treatment of 148 patients with BPF post-pulmonary resection in which they used customized self-expandable covered metallic stents to occlude the fistula (58). Stent customization was performed based on measurements acquired by chest CT, bronchoscopy and bronchography with water-soluble contrast. Stent shape (Y-shaped, L-shaped or hinged) was based on the fistula location and bronchial stump length. The stent was correctly placed in the first attempt in $96.6 \%$ of the patients, resulting in complete occlusion of the fistula and short-term relief of clinical manifestations in 141 
patients. Seventy-three patients were considered cured with complete obliteration of the pleural cavity and had their stent removed after a mean of 110 days. The success rate was higher for post-lobectomy fistulae $(85 \%)$ than postpneumonectomy fistulae (38\%). The major complication rate was low, however, proliferation of granulation tissue at the extremity of the stent was a problem, which led to respiratory symptoms due to airway obstruction and ultimately to stent removal in 51 patients.

\section{Transpleural approach}

After the infection in the pleural cavity is under control, surgical closure of BPFs is commonly attempted through conventional thoracotomy or open window thoracotomy. The first step is to identify the fistula's size and location and evaluate the presence of necrosis. Then, debridement of devitalized tissue is performed. Dissection of the bronchial stump can be challenging depending on the level of local fibrosis and proximity to important structures, commonly the pulmonary artery. When bronchial stump dissection is feasible and safe, the fistula may be directly closed with absorbable or non-absorbable sutures or even stapled in cases of long stumps, which are more common in acute BPF (59). After a standard closure, reinforcement of the closed BPF should be done with muscle flap or other vascularized tissue, such as omentum (60-62). In circumstances where the bronchial stump is not amenable to dissection, BPF closure may be accomplished by creating a "plug" with a muscle flap. A series from the Mayo Clinic reported the outcomes of 55 patients with BPF closure using muscle flaps and demonstrated a success rate of $82 \%$. Bronchial stump closure and reinforcement with a serratus anterior muscle flap was the most used technique.

\section{Transsternal transpericardial approach}

In situations where the access to the bronchial stump is not feasible through the conventional transpleural approach, a transsternal transpericardial approach might be undertaken (59). This approach can be useful in patients with a prior attempt of BPF closure by thoracotomy or with a very short stump, mainly seen after a BPF caused by a left pneumonectomy. After a standard median sternotomy, the anterior pericardium is opened, and the superior vena cava and aorta are retracted laterally. The right pulmonary artery is retracted inferiorly. A window is made in the posterior pericardium, and good exposure of the carina and main bronchi is obtained to allow safe manipulation of the bronchial stump (63). In a retrospective series of 55 patients, De la Riviere and colleagues reported recurrence of BPF in $23.6 \%$ of patients using this approach (64). Whereas, Topcuoglu and coworkers described a success rate of $100 \%$ with no recurrence in 15 patients (65).

\section{Conclusions}

After pneumonectomy, patients who develop the complications of BPF and empyema exhibit high morbidity and mortality rates. The management of the BPF is a challenge. Accurate and expedited diagnosis is critical to achieve a cure. Regardless of the technique adopted for treatment, adequate pleural drainage, definitive closure of the BPF, sterilization of the pleural cavity, and obliteration of residual space are the key factors to favorable outcomes. Less invasive techniques, when clearly indicated and in selected patients, seem to be a good strategy and do not preclude the possibility of a more aggressive approach, if warranted.

\section{Acknowledgments}

Funding: None.

\section{Footnote}

Provenance and Peer Review: This article was commissioned by the Guest Editors (Lorenzo Spaggiari \& Luca Bertolaccini) and the editorial office for the series "The Role of Pneumonectomy in Thoracic Surgery in The Third Millennium" published in Shanghai Chest. This article has undergone external peer review.

Conflicts of Interest: All authors have completed the ICMJE uniform disclosure form (available at http://dx.doi. org/10.21037/shc.2020.03.11). The series "The Role of Pneumonectomy in Thoracic Surgery in The Third Millennium" was commissioned by the editorial office without any funding or sponsorship. The authors have no other conflicts of interest to declare.

Ethical Statement: The author is accountable for all aspects of the work in ensuring that questions related to the accuracy or integrity of any part of the work are appropriately investigated and resolved.

Open Access Statement: This is an Open Access article distributed in accordance with the Creative Commons 
Attribution-NonCommercial-NoDerivs 4.0 International License (CC BY-NC-ND 4.0), which permits the noncommercial replication and distribution of the article with the strict proviso that no changes or edits are made and the original work is properly cited (including links to both the formal publication through the relevant DOI and the license). See: https://creativecommons.org/licenses/by-nc-nd/4.0/.

\section{References}

1. James TW, Faber LP. Indications for pneumonectomy. Pneumonectomy for malignant disease. Chest Surg Clin N Am 1999;9:291-309.

2. Dyszkiewicz W, Pawlak K, Gasiorowski L. Early postpneumonectomy complications in the elderly. Eur J Cardiothorac Surg 2000;17:246-50.

3. Zaheer S, Allen MS, Cassivi SD, et al. Postpneumonectomy Empyema: Results After the Clagett Procedure. Ann Thorac Surg 2006;82:279-86.

4. Schneiter D, Cassina P, Korom S, et al. Accelerated treatment for early and late Postpneumonectomy empyema. Ann Thorac Surg 2001;72:1668-72.

5. Shamji FM, Ginsberg RJ, Cooper JD. Open window thoracostomy in the management of post-pneumonectomy empyema with or without bronchopleural fistula. J Thorac Cardiovasc Surg 1983;86:818-22.

6. Galetta D, Spaggiari L. Video-Thoracoscopic Management of Postpneumonectomy Empyema. Thorac Cardiovasc Surg 2018;66:701-6.

7. Ahmed AE, Yacoub TE. Empyema thoracis. Clin Med Insights Circ Respir Pulm Med 2010;4:1-8.

8. Li SJ, Zhou XD, Huang J, et al. A systematic review and meta-analysis-does chronic obstructive pulmonary disease predispose to bronchopleural fistula formation in patients undergoing lung cancer surgery? J Thorac Dis 2016;8:1625-38.

9. Sirbu H, Busch T, Aleksic I, et al. Bronchopleural fistula in the surgery of non-small cell lung cancer: incidence, risk factors, and management. Ann Thorac Cardiovasc Surg 2001;7:330-6.

10. Hu XF, Duan L, Jiang GN, et al. A clinical risk model for the evaluation of bronchopleural fistula in non-small cell lung cancer after pneumonectomy. Ann Thorac Surg 2013;96:419-24.

11. Algar FJ, Alvarez A, Aranda JL, et al. Prediction of early bronchopleural fistula after pneumonectomy: a multivariate analysis. Ann Thorac Surg 2001;72:1662-7.

12. Panagopoulos ND, Apostolakis E, Koletsis E, et al. Low incidence of bronchopleural fistula after pneumonectomy for lung cancer. Interact Cardiovasc Thorac Surg 2009;9:571-5.

13. Khan JH, Rahman SB, McEihinney DB, et al. Management strategies for complex bronchopleural fistula. Asian Cardiovasc Thorac Ann 2000;8:78-84.

14. Darling GE, Abdurahman A, Yi QL, et al. Risk of a right pneumonectomy: role of bronchopleural fistula. Ann Thorac Surg 2005;79:433-7.

15. Hubaut JJ, Baron O, Al Habash O, et al. Closure of the bronchial stump by manual suture and incidence of bronchopleural fistula in a series of 209 pneumonectomies for lung cancer. Eur J Cardiothorac Surg 1999;16:418-23.

16. Deschamps C, Bernard A, Nichols FC 3rd, et al. Empyema and bronchopleural fistula after pneumonectomy: factors affecting incidence. Ann Thorac Surg 2001;72:243-7; discussion 248.

17. Wright CD, Wain JC, Mathisen DJ, et al. Postpneumonectomy bronchopleural fistula after sutured bronchial closure: incidence, risk factors, and management. J Thorac Cardiovasc Surg 1996;112:1367-71.

18. Pairolero PC, Arnold PG, Trastek VF, et al. Postpneumonectomy empyema. The role of intrathoracic muscle transposition. J Thorac Cardiovasc Surg 1990;99:958-66.

19. Schneiter D, Grodzki T, Lardinois D, et al. Accelerated treatment of postpneumonectomy empyema: A binational long-term study. J Thorac Cardiovasc Surg 2008;136:179-85.

20. Clagett OT, Geraci JE. A procedure for the management of postpneumonectomy empyema. J Thorac Cardiovasc Surg 1963;45:141-5

21. Eloesser L. An operation for tuberculous empyema. Surg Gynecol Obs 1935;60:1096-7.

22. Conlan AA, Kopec SE. Indications for pneumonectomy. Pneumonectomy for benign disease. Chest Surg Clin N Am 1999;9:311.

23. Symbas PN, Nugent JT, Abbott OA, et al. Nontuberculous Pleural Empyema in Adults. Ann Thorac Surg 1971;12:69-78.

24. Denlinger, Chadrick E. Eloesser Flap Thoracostomy Window. Oper Tech Thorac Cardiovasc Surg, 2010;15:61-9.

25. Stafford EG, Clagett OT. Postpneumonectomy empyema: neomycin instillation and definitive closure. J Thorac Cardiovasc Surg 1972;63:771-5.

26. Miller JI, Mansour KA, Nahai F, et al. SingleStage Complete Muscle Flap Closure of the 
Postpneumonectomy Empyema Space: A New Method and Possible Solution to a Disturbing Complication. Ann Thorac Surg 1984;38:227-31.

27. Abrashoff Plastische Method der Schiessung von Fistelgangen, cZentralbl Chir 38186, 1911.

28. Babu AN, Mitchell JD. Technique of Muscle Flap Harvest for Intrathoracic Use. Oper Tech Thorac Cardiovasc Surg 2010;15:41-52.

29. Mathes SJ, Nahai F. Clinical Applications for Muscle and Musculocutaneous Flaps. St. Louis, Mosby, 1982.

30. Alexander J. The collapse therapy of pulmonary tuberculosis. Springfield, IL: Charles C Thomas, 1937.

31. Icard P, Le Rochais JP, Rabut B, et al. Andrews Thoracoplasty as a treatment of post- pneumonectomy empyema: experience in 23 cases. Ann Thorac Surg 1999;68:1159-63.

32. Garcia-Yuste M, Ramos G, Duque JL, et al. Open-window thoracostomy and thoracomyoplasty to manage chronic pleural empyema. Ann Thorac Surg 1998;65:818-22.

33. Semb C. Thoracoplasty with apicolysis. Oslo: Nationaltryk- keriet, 1935.

34. Barker WL. Thoracoplasty. Chest Surg Clin N Am 1994;4:593-615.

35. Hakim M, Milstein BB. Empyema thoracic and infected pneumonectomy space: case for cyclical irrigation. Ann Thorac Surg 1986;41:85.

36. Rosenfeldt FL, McGibney D, Braimbridge MV, et al. Comparison between irrigation and conventional treatment for empyema and pneumonectomy space infection. Thorax 1981;36:272.

37. Gharagozloo F, Trachiotis G, Wolfe A, et al. Pleural space irrigation and modified Clagett procedure for the treatment of early postpneumonectomy empyema. J Thorac Cardiovasc Surg 1998;116:943-8.

38. Hollaus PH, Lax F, Wurnig PN, et al. Videothoracoscopic debridement of the postpneumonectomy space in empyema. Eur J Cardiothorac Surg 1999;16:283-6.

39. Podbielski FJ, Halldorsson AO, Vigneswaran WT. Video-assisted thoracoscopic management of postpneumonectomy empy- ema. JSLS 1997;1:255-8.

40. Ernst M, Nies C. Die thoracoskopische therapie des pleu- raempyems nach pneumonektomie. Chirurg 1999;70:1480-3.

41. Gossot D, Stern JB, Galetta D, et al. Thoracoscopic management of postpneumonectomy empyema. Ann Thorac Surg 2004;78:273-6.
42. Hollaus PH, Lax F, Janakiev D, et al. Endoscopic treatment of postoperative bronchopleural fistula: experience with 45 cases. Ann Thorac Surg 1998;66:923-7.

43. Cardillo G, Carbone L, Carleo F, et al. The Rationale for Treatment of Postresectional Bronchopleural Fistula: Analysis of 52 Patients. Ann Thorac Surg 2015;100:251-7.

44. Scappaticci E, Ardissone F, Ruffini E, et al. As originally published in 1994: Postoperative bronchopleural fistula: endoscopic closure in 12 patients. Updated in 2000. Ann Thorac Surg 2000;69:1629-30.

45. Hamid UI, Jones JM. Closure of a bronchopleural fistula using glue. Interact Cardiovasc Thorac Surg 2011;13:117-8.

46. Ranu H, Gatheral T, Sheth A, et al. Successful endobronchial seal of surgical bronchopleural fistulas using BioGlue. Ann Thorac Surg 2009;88:1691-2.

47. Roksvaag H, Skalleberg L, Nordberg C, et al. Endoscopic closure of bronchial fistula. Thorax 1983;38:696-7.

48. Menard JW, Prejean CA, Tucker WY. Endoscopic closure of bronchopleural fistulas using a tissue adhesive. Am J Surg 1988;155:415-6.

49. Varoli F, Roviaro G, Grignani F, et al. Endoscopic treatment of bronchopleural fistulas. Ann Thorac Surg 1998;65:807-9.

50. Boudaya MS, Smadhi H, Zribi H, et al. Conservative management of postoperative bronchopleural fistulas. J Thorac Cardiovasc Surg 2013;146:575-9.

51. Stratakos G, Zuccatosta L, Porfyridis I, et al. Silver nitrate through flexible bronchoscope in the treatment of bronchopleural fistulae. J Thorac Cardiovasc Surg 2009;138:603-7.

52. Varoli F, Roviaro G, Grignani F, Vergani C, Maciocco M, Rebuffat C. Endoscopic treatment of bronchopleural fistulas. Ann Thorac Surg 1998;65:807-9.

53. Kramer MR, Peled N, Shitrit D, et al. Use of Amplatzer device for endobronchial closure of bronchopleural fistulas. Chest 2008;133:1481-4

54. Han YM, Gu X, Titus JL, et al. New self-expanding patente foramen ode occlusion device. Catheter Cardiovasc Interv 1999;47:370-6.

55. Fruchter O, Kramer MR, Dagan T, et al. Endobronchial closure of bronchopleural fistulae using amplatzer devices: our experience and literature review. Chest 2011;139:682-7.

56. Fruchter O, Bruckheimer E, Raviv Y, et al. Endobronchial closure of bronchopleural fistulas with Amplatzer vascular 
plug. Eur J Cardiothorac Surg 2012;41:46-9.

57. Fruchter O, El Raouf BA, Abdel-Rahman N, et al. Efficacy of bronchoscopic closure of a bronchopleural fistula with amplatzer devices: long-term follow-up. Respiration 2014;87:227-33.

58. Han X, Yin M, Li L, et al. Customized airway stenting for bronchopleural fistula after pulmonary resection by interventional technique: single-center study of 148 consecutive patients. Surg Endosc 2018;32:4116-24.

59. Bribriesco A, Patterson GA. Management of Postpneumonectomy Bronchopleural Fistula: From Thoracoplasty to Transsternal Closure. Thorac Surg Clin 2018;28:323-35.

60. García-Yuste M, Matilla JM, Cueto A, et al. Typical and atypical carcinoid tumours: analysis of the experience of the Spanish Multi-centric Study of Neuroendocrine Tumours of the Lung. Eur J Cardiothorac Surg 2007;31:192-7.

doi: 10.21037/shc.2020.03.11

Cite this article as: Azevedo I, Oliveira RL, Ugalde PA. Management of postpneumonectomy empyema and bronchopleural fistula. Shanghai Chest 2021;5:15.
61. Ahmad U, Chumakova M, Raja S, et al.

Postpneumonectomy bronchopleural fistula closure with biologic mesh and diaphragm flap. Ann Thorac Surg 2017;104:e215-6.

62. Regnard JF, Alifano M, Puyo P, et al. Open window thoracostomy followed by intrathoracic flap transposition in the treatment of empyema complicating pulmonary resection. J Thorac Cardiovasc Surg 2000;120:270-5.

63. Abruzzini P. Trattamento chirurgico delle fistole del bronco principale consecutive a pneumonectomia per tubercolosi. Chirur Torac 1961;14:165-71.

64. de la Riviere AB, Defauw JJ, Knaepen PJ, et al. Transsternal closure of bronchopleural fistula after pneumonectomy. Ann Thorac Surg 1997;64:954-7.

65. Topcuoglu MS, Kayhan C, Ulus T. Transsternal transpericardial approach for the repair of bronchopleural fistula with empyema. Ann Thorac Surg 2000;69:394. 